\title{
Tissue-derived mesenchymal stromal cells used as vehicles for anti-tumor therapy exert different in vivo effects on migration capacity and tumor growth
}

Carolina Belmar-Lopez ${ }^{1}$, Gracia Mendoza ${ }^{1}$, Daniel Oberg ${ }^{2}$, Jerome Burnet ${ }^{3}$, Carlos Simon ${ }^{4}$, Irene Cervello ${ }^{4}$, Maite Iglesias ${ }^{5}$, Juan Carlos Ramirez ${ }^{6}$, Pilar Lopez-Larrubia ${ }^{7}$, Miguel Quintanilla ${ }^{7}$ and Pilar Martin-Duque ${ }^{1,5,8^{*}}$

\begin{abstract}
Background: Mesenchymal stem cells (MSCs) have been promoted as an attractive option to use as cellular delivery vehicles to carry anti-tumor agents, owing to their ability to home into tumor sites and secrete cytokines. Multiple isolated populations have been described as MSCs, but despite extensive in vitro characterization, little is known about their in vivo behavior.

The aim of this study was to investigate the efficacy and efficiency of different MSC lineages derived from five different sources (bone marrow, adipose tissue, epithelial endometrium, stroma endometrium, and amniotic membrane), in order to assess their adequacy for cell-based anti-tumor therapies. Our study shows the crucial importance of understanding the interaction between MSCs and tumor cells, and provides both information and a methodological approach, which could be used to develop safer and more accurate targeted therapeutic applications.
\end{abstract}

Methods: We first measured the in vivo migration capacity and effect on tumor growth of the different MSCs using two imaging techniques: (i) single-photon emission computed tomography combined with computed tomography (SPECT-CT), using the human sodium iodine symporter gene (hNIS) and (ii) magnetic resonance imaging using superparamagnetic iron oxide. We then sought correlations between these parameters and expression of pluripotency-related or migration-related genes.

Results: Our results show that migration of human bone marrow-derived MSCs was significantly reduced and slower than that obtained with the other MSCs assayed and also with human induced pluripotent stem cells (hiPSCs). The qPCR data clearly show that MSCs and hiPSCs exert a very different pluripotency pattern, which correlates with the differences observed in their engraftment capacity and with their effects on tumor growth.

Conclusion: This study reveals differences in MSC recruitment/migration toward the tumor site and the corresponding effects on tumor growth. Three observations stand out: 1) tracking of the stem cell is essential to check the safety and efficacy of cell therapies; 2) the MSC lineage to be used in the cell therapy needs to be carefully chosen to balance efficacy and safety for a particular tumor type; and 3) different pluripotency and mobility patterns can be linked to the engraftment capacity of the MSCs, and should be checked as part of the clinical characterization of the lineage.

Keywords: Mesenchymal stromal cells, Migration, In vivo imaging, Tumor growth, Pluripotency

\footnotetext{
* Correspondence: p.martin@ufv.es

1 Instituto Aragones de Ciencias de la Salud-IIS Aragon, Zaragoza, Spain

${ }^{5}$ Facultad de Ciencias Biosanitarias, Universidad Francisco de Vitoria, Madrid,

Spain

Full list of author information is available at the end of the article
} 


\section{Background}

Human mesenchymal stem cells or mesenchymal stromal cells (MSCs) are multipotent progenitor cells or adult stem cells that exhibit the ability to migrate and engraft into tumor sites when delivered systemically [1]. However, determining the most appropriate clinical application of MSCs is hampered by the current lack of knowledge about how these cells behave in vivo. The precise mechanisms behind the recruitment of MSCs to tumor sites and their migration across the endothelium are not yet fully understood. It is probable that damaged tissue expresses specific receptors or ligands to make possible trafficking, adhesion, and extravasation of MSCs to the site of damage and recruitment to inflammation sites, using a mechanism similar to leukocyte migration [2-4].

The most likely cause of specific migration is the release of chemotactic gradients from the tumors, which may enable MSCs to home to, and modulate, the tumor microenvironment $[5,6]$. Owing to these properties and their ability to modulate the activity of immune cells, MSCs could function as cellular delivery vehicles for anti-tumor agents [7-9].

MSCs were first identified in the 1960s in the stromal compartment of bone marrow [10,11], and since then, they have been isolated from a wide variety of adult [12-20] and fetal (both first and second trimester) tissues, including blood, liver, bone marrow, placenta, and umbilical cord [21-25], using similar techniques [26]. The best-characterized source for adult human stem cells is bone marrow, and both bone marrow-derived human MSCs (BM-hMSCs) and adipose-derived human MSCs (hASCs) have become attractive candidates because these tissues are rich sources of MSCs and are easy to collect. The other tissue-derived MSCs share a number of important characteristics with BM-hMSCs, including expression of cell surface marker, ability to adhere to plastic, and capacity to differentiate into cells of mesenchymal lineage under appropriate conditions [27]. Despite extensive investigations, the effect of unmodified MSCs on tumor progression remains unclear. Many studies have shown that MSCs promote tumor progression and metastasis, whereas others have reported that MSCs suppress tumor growth [28]. The contradictions in these findings may be attributable to the variability and heterogeneity in adult stem cells from different sources, or to differences in isolation methods and in vitro culture conditions. Further development of an efficient and safe cell-based therapy will require the in vivo tracking of engrafted MSCs to ensure that they reach their destination. In vivo imaging techniques provide a continuum observation rather than a single snapshot of conventional post-mortem histological analyses.

The aim of our work was to investigate the efficacy and efficiency of five different MSC lineages, in order to assess their adequacy for use as cell-based anti-tumor therapies. Our study shows the crucial importance of understanding the interaction between MSCs and tumor cells, and provides both information and a methodological approach, which could be used to develop safer and more accurately targeted therapeutic applications. The pluripotency expression pattern of MSCs was studied and compared with that obtained in human induced pluripotent stem cells (hiPSCs). Furthermore, the effects exerted on migration-related gene expression in tumors obtained from animals after 24 days of systemic MSC injection were also analyzed.

\section{Methods}

\section{Cell cultures}

A human cervical cancer cell line (HeLa; Cancer Research UK Cell Services, London Research Institute, Clare Hall Laboratories, Herts, UK) and human PN3 fibroblasts (kindly supplied by Dr Liu (Imperial College, London, UK)) were used. Cells were cultured in DMEM containing $10 \%$ FBS and antibiotics (Lonza, Verviers, Belgium), at $37^{\circ} \mathrm{C}$ in $5 \% \mathrm{CO}_{2}$.

All MSC media were supplemented with 10\% FBS and antibiotics. BM-hMSCs were obtained from Lonza and maintained in DMEM low glucose $(1.0 \mathrm{~g} / \mathrm{l})$ and hypoxic conditions $\left(3 \% \mathrm{O}_{2}\right)$. hASCs were obtained from Invitrogen (UK) and cultured in MesenPro RS Basal Medium and MesenPro RS Growth Supplement (Gibco, Paisley, UK). Human epithelial endometrium-derived stem cells or hEESCs (also known as endometrial epithelial stem cell lines; ICEp) and human stroma endometrium-derived stem cells or hESSCs (also known as endometrial stromal stem cell lines; ICEs) were supplied by Dr Carlos Simon from IVI (Valencia, Spain) [12,13]. Cells were maintained in DMEM F-12 under hypoxic conditions $\left(3 \% \mathrm{O}_{2}\right)$ and dishes were pre-treated with $0.1 \%$ gelatin solution (SigmaAldrich Chemie GmBh, Munich, Germany). Human amniotic membrane mesenchymal stem cells or hAMCs were obtained from Cellular Engineering Technologies (CET), (Coralville, IA, USA) and were maintained in DMEM high glucose $(4.5 \mathrm{~g} / \mathrm{l})$ and $10 \mathrm{ng} / \mathrm{ml}$ basic human fibroblast growth factor (hFGFb;Gibco). Cells were used between passages 5 to 8 .

The hiPSCs (human IPSC line 2 F8) were kindly supplied by Dr Austin Smith (University of Cambrige, UK) and cultured in knockout DMEM (Gibco), 15\% knockout serum (Gibco), 1× NEAA (Lonza), $0.1 \mathrm{mmol} / \mathrm{l} \beta$-mercaptoethanol

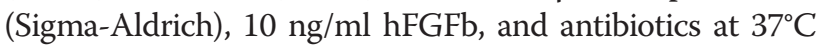
in $5 \% \mathrm{CO}_{2}$. Cells were seeded on a PN3 feeder cell monolayer inactivated with mitomycin C (Sigma-Aldrich).

\section{Flow-cytometry analysis}

Characterization of MSCs was verified by flow cytometry. The negative surface markers used were CD45, CD34, and HLA-DR, and the positive ones were CD90, 
CD73, and CD105, plus CD9 and CD13 (the last two markers refers only to hEESCs and hESSCs, respectively). The antibodies used were CD13 FITC-conjugated (Immunostep, Salamanca, Spain), CD34 Percp/Cy5.5conjugated (Becton Dickinson Co., Madrid, Spain), CD9 PE-conjugated (Millipore Corp., Billerica, MA, USA), CD45 PerCP/Cy5.5-conjugated (Becton Dickinson), CD73 PE-conjugated (BD), CD90 PE-conjugated (Becton Dickinson), CD105 FITC-conjugated (R\&D Systems Inc., Minneapolis, MN, USA), and HLA-DR APCconjugated (Immunostep). Briefly, cells were incubated in PBS supplemented with $2 \%$ FBS and specific antibodies at $4^{\circ} \mathrm{C}$ for 30 minutes. Then, cells were washed and fixed in $1 \%$ paraformaldehyde (Sigma-Aldrich) before FACS analysis (FACSAria system; Becton Dickinson).

\section{In vitro MSC differentiation}

For adipogenesis, MSCs were kept for 21 days in $1 \times$ basal medium (STEMPRO ${ }^{\circ}$ Adipocyte Differentiation Basal Medium; Invitrogen Corp., Carlsbad, CA, USA), 1× supplement (STEMPRO ${ }^{\circ}$ Adipogenesis Supplement; Invitrogen) and antibiotics. When differentiation was finished, cells were stained with Oil Red O solution (Sigma-Aldrich). For osteogenesis, MSCs were maintained for two weeks in DMEM medium containing 10\% FBS, $50 \mu \mathrm{g} / \mathrm{ml}$ ascorbic acid, $100 \mathrm{nmol} / \mathrm{l}$ dexamethasone, and $10 \mathrm{mmol} / \mathrm{l} \beta$ glycerophosphate disodium salt hydrate (Sigma-Aldrich) and antibiotics. Osteocyte formation was evaluated by staining with Alizarin Red S (Sigma-Aldrich). Images were visualized under a microscope (AE31; Motic Group Co. Ltd, Causeway Bay, Hong Kong) equipped with a camera (2500 Moticam; Motic Group) and Motic Imaging Plus 2 software (version 0.23).

\section{Adenoviral vectors and infections}

The hNIS gene is endogenously expressed mainly in the thyroid and stomach, and is responsible for iodide concentration. In cells expressing hNIS, gamma rayemitting radioisotopes such as ${ }^{99 \mathrm{~m}} \mathrm{Tc}$ are accumulated, and can be imaged by SPECT-CT, and thus the hNIS gene can be used as a reporter gene [29]. The adenoviral vector AdhNIS (also known as Ad10) used in this work was based on adenovirus serotype 5 , and the hNIS gene is driven by the immediate-early cytomegalovirus promoter. AdhNIS was constructed and amplified as previously described [30]. The amount of infective adenoviral vector per cell (pFUs/cells) in culture media was expressed as multiplicity of infection (MOI). Previously, adenoviral infection efficiency was determined using adenoviral vector AdGFP testing at 100, 250, 500, and $1000 \mathrm{MOI}$, as in our previous study [31] (data not shown). For the adenoviral infection with AdhNIS, viruses were diluted in serum-free culture media to $500 \mathrm{MOI}$, added to cells, and incubated at $37^{\circ} \mathrm{C}$ for $1 \mathrm{~h}$. The complete medium was then added and cells were maintained for $24 \mathrm{~h}$ until used in the in vivo experiments.

\section{Ethics approval}

All procedures were carried out under a project license approved by the Ethics Committee for Animal Experiments from the University of Zaragoza (Spain). The care and use of animals was performed in accordance with the Spanish Policy for Animal Protection RD1201/05.

\section{Experimental in vivo design}

Female BALB/c nu/nu mice 6-8 weeks old (Harlan UK Ltd (Bicester, Oxfordshire, UK) and Harlan Interfauna Iberica (Barcelona, Spain)) received subcutaneous (SC) injections of $2 \times 10^{6}$ HeLa cells suspended in $200 \mu \mathrm{l} \mathrm{PBS}$ for the generation of subcutaneous xenograft tumors. When these tumors reached $50 \mathrm{~mm}^{3}$ in size, mice were randomly divided into different groups, and intravenous injections of MSC were performed. For MRI experiments, animals were separated into six groups $(n=4 /$ group). Group 1 (BM-hMSCs injected); group 2 (hASCs injected); group 3 (hAMCs injected); group 4 (hESSCs injected); group 5 (hEESCs injected); and group 6 (control; PBS injected). For SPECT-CT experiments, animals were separated into seven groups ( $n=4 /$ group), with groups 1 to 5 as above, and groups 6 and 7 being injected with hiPSCs or PBS (control), respectively.

\section{Iron-oxide labeling and cell-viability assay}

MSCs were magnetically labeled with superparamagnetic iron oxide (SPIO; Endorem, Guerbet, France), as previously described [32]. SPIO is an oxide nanoparticle solution with a total iron content of $11.2 \mathrm{mg} \mathrm{Fe} / \mathrm{ml}$. Labeling with SPIO acts by reducing the transverse relaxation time on T2-weighted MRI scans. Cells were incubated with the labeling medium containing $100 \mu \mathrm{g} / \mathrm{ml}$ iron for $24 \mathrm{~h}$. After labeling, cells were washed to remove residual contrast agent.

Viability of the iron oxide-labeled MSCs was evaluated by performing a long-term (10 days) in vitro exclusion test with Trypan blue (Sigma-Aldrich).

\section{MRI}

Animals bearing the tumor xenograft were separated into six groups ( $n=4$ /group) when the tumors reached $50 \mathrm{~mm}^{3}$. MSCs were labeled with SPIO as described above. Groups 1 to 5 received an intravenous injection of $10^{6}$ SPIO-labeled MSCs, while the control group (group 6) received intravenous injection of PBS. Scans were performed at $3,10,17$, and 24 days after injection. The MRI experiments were performed (Pharmascan system; Bruker Medical GmBH, Germany, http://www. bruker-biospin.com/pharmascan.html) using a 7.0-T horizontal-bore superconducting magnet, equipped with 
a ${ }^{1} \mathrm{H}$ selective surface coil and a Bruker gradient insert with $90 \mathrm{~mm}$ inner diameter (maximum intensity 360 $\mathrm{mT} / \mathrm{m})$. All data were acquired using Paravision software (Bruker). Anesthesia was initiated using oxygen (1 l/min) containing $4 \%$ isofluorane, and maintained during the experiment with 1 to $1.5 \%$ isofluorane in $\mathrm{O}_{2}$. T2-weighted spin-echo anatomical images were acquired by rapid acquisition with relaxation enhancement (RARE) sequence in axial (12 slices) and sagittal (8 slices) orientations and the following parameters: TR 3000 $\mathrm{ms}$, TE $60 \mathrm{~ms}$, RARE factor 8 , average 3 , FOV $30 \times 30$ mm, acquisition matrix $256 \times 256$, corresponding to an in-plane resolution of $117 \times 117 \mu^{2}$ and slice thickness of $1.00 \mathrm{~mm}$. Tumors were measured every 2 days and tumor volume was calculated using the formula:

tumor volume $=1 / 2 \mathrm{~L} \times \mathrm{S}^{2}$, where $\mathrm{L}$ is long side and $\mathrm{S}$ is short side.

\section{Prussian blue staining and histological analysis}

At day 24, the animals in the in vivo MRI experiments were euthanized. Tumors and tissues were obtained, fixed in formalin, and embedded in paraffin wax. Sections of $4 \mu \mathrm{m}$ were obtained from the blocks for staining with haematoxylin and eosin (Sigma-Aldrich). Staining with Prussian blue (Sigma-Aldrich) was used to detect labeled iron particles in the cells, in accordance with the manufacturer's instructions. The number of blue-stained (positive) cells per high-power field (HPF) was calculated by counting the cells in at least five HPFs per section, with a minimum of five sections per sample examined.

\section{SPECT-CT imaging}

Animals bearing tumor xenograft were separated into seven groups ( $n=4 /$ group) when the tumors reached $50 \mathrm{~mm}^{3}$. MSCs were infected with AdhNIS as described above. Groups 1 to 6 received intravenous injection of $10^{6}$ hNIS-labeled MSCs and the control group (group 7) received intravenous injection of PBS. At 3, 10, 17, and 24 days post-injection, all groups received an intravenous dose of $18.5 \mathrm{MBq}$ of ${ }^{99 \mathrm{~m}} \mathrm{Tc}$. Anesthesia was initiated by inhaled oxygen $(1 \mathrm{l} / \mathrm{min})$ containing $4 \%$ isofluorane, and maintained during the experiment with 1 to $1.5 \%$ isofluorane in $\mathrm{O}_{2}$. The mice were scanned using a nanoSPECT-CT scanner for small animals (Bioscan, Paris, France). A tomogram was taken, and the limits of the scan were determined. A CT and a SPECT whole-body scan were performed, with a time of 100 seconds per acquisition. The images were reconstructed with the MEDISO software (Medical Imaging Systems, Budapest, Hungary); fusion of SPECT and CT images was carried out using PMOD software (Biomedical Imagen Quantification, Basel, Switzerland). Tumors were measured every two days and tumor volume was calculated using the formula for tumor volume given above.
Quantification of radioisotope $\left({ }^{99 \mathrm{~m}} \mathrm{Tc}\right)$ accumulation was carried out using InVivoScope software (Medical Imaging Systems). Fused SPECT/CT images were used to draw the voxel-guided specific volume of interest (VOI) to accurately quantify the total activity associated with the whole tumor volume. Quantification of ${ }^{99 \mathrm{~m}} \mathrm{Tc}$ accumulation was expressed as ratio of tumor uptake to muscle uptake.

\section{Reverse transcription-PCR}

Total RNA was isolated from tumors from the in vivo SPECT-CT experiment using a commercial kit (NucleoSpin RNA II Kit; Macherey-Nagel GmBH, Dueren, Germany), in accordance with the manufacturer's instructions. Total RNA was reverse-transcribed to cDNA (SuperScript II Reverse transcriptase; Invitrogen). Control reactions were performed by omitting the reverse transcriptase. Reverse transcription (RT)-PCR was carried out using hNISspecific and GAPDH-specific primers (Table 1). PCR was performed using an automated system (Applied Biosystems 2720 Thermal Cycle System; Life Technologies, Glasgow, UK). cDNA products were separated by electrophoresis.

\section{Real-time quantitative PCR Pluripotency-related genes}

Real-time quantitative PCR (qPCR) was performed to analyze expression of NANOG, SOX2, OCT4, KLF4, and REX1. To detect gene expression, MSCs and hiPSCs were lysed directly in the culture dishes, then total RNA was extracted and reverse transcription to cDNA was carried out as described above. To test the quality of the cDNA, mRNA of the housekeeping GADPH was amplified. RNA from hiPSCs was used as pluripotency control. Reactions were performed using a master mix (Taqman Universal Master Mix II; Invitrogen) and a PCR system (Applied Biosystems 7900HT Fast-Real Time PCR System; Life Technologies) with probes (Applied Biosystems. Foster City, CA, USA) (Table 2). Gene expression levels were normalized against $18 \mathrm{~S}$ rRNA. The ratio of the relative expression for each gene to $18 \mathrm{~S}$ was calculated by the $2^{-\Delta \Delta \mathrm{Cq}}$ formula. The hiPSC data were used as a calibrator for the results presented $\left(2^{-\Delta \Delta \mathrm{Cq}}=100 \%\right)$.

\section{Table 1 Primers used for PCR}

\begin{tabular}{ccc}
\hline Primer & Direction & Sequence $\mathbf{5}^{\prime} \boldsymbol{\rightarrow} \mathbf{3}^{\prime}$ \\
\hline hNIS & Sense & CCCATCGATGGAGGCCGTGGAGACCGG \\
& Anti-sense & CCCATCGATGTCAGAGGTTTGTCTCCTGC \\
GADPH & Sense & CCCATCGATGTCAGAGGTTGTCTCCTGC \\
& Anti-sense & GGTCATGAGTCCTTCCACGAT \\
\hline
\end{tabular}

GADPH glyceraldehyde-3-phosphate dehydrogenase, $h N I S$ human sodium iodine symporter. 


\section{Migration-related genes}

qPCR was performed to analyze expression of CXCL12 (SDF-1), CXCR4, MMP-2, CCL2 (MCP-1), and CCL5 (RANTES) (Sigma-Aldrich) (Table 3). To detect and quantify gene expression, total RNA from tumors consisting only of HeLa cells (control group) and tumors consisting of HeLa cells with MSCs or hiPSCs injected intravenously were isolated and then reverse-transcribed to cDNA. Reactions were performed using SYBR Green (Power SYBR Green PCR Master Mix; Life Technologies) and a real-time PCR system (Applied Biosystems 7500; Life Technologies). Reactions were performed in duplicate from three different dilutions, and threshold cycle values were normalized to the housekeeping gene $18 \mathrm{~S}$. The specificity of the products was determined by melting curve analysis and gel electrophoresis. The ratio of the fold difference expression for each gene to $18 \mathrm{~S}$ was calculated using the ${ }^{-\Delta \Delta} \mathrm{Cq}$ formula. Gene expression levels were normalized against $18 \mathrm{~S}$ rRNA and the expression obtained from the control group was used as a calibrator $\left({ }^{-\Delta \Delta} \mathrm{Cq}=0\right)$.

\section{Statistical analysis}

Results are reported as mean \pm SEM. Statistical evaluation of data was carried out using the SPSS Statistics software package (version 17.0; IBM SPSS, Chicago, IL, USA). Normal distribution of the variables was analyzed by means of the Kolmogorov-Smirnov test followed by the Tukey HSD test, except for KLF4 and REX1 expression in the pluripotency qPCR assays, whose distribution was non-parametric and so analysis was performed using the Kruskal-Wallis test. $P<0.05$ was considered significant.

\section{Results}

To confirm whether labeled MSCs injected systemically into animals are able to migrate, proliferate, and engraft into the microenvironment of tumors, two non-invasive imaging techniques were performed in the present study: 1) SPECT-CT using hNIS as reporter gene, and 2) MRI labeled with iron nanoparticles (SPIO).

Before performing specific studies, it was tested whether these cells gave rise to adipocytes and osteoblasts when they were placed in specific differentiating

Table 2 TaqMan ${ }^{\circledR}$ gene expression assays used to amplify the pluripotency-related genes

\begin{tabular}{cccc}
\hline Gene & Assay ID & Amplicon size, nucleotides & Dye \\
\hline NANOG & Hs02387400_g1 & 109 & FAM \\
SOX2 & Hs01053049_s1 & 91 & FAM \\
OCT4 & Hs00742896_s1 & 65 & FAM \\
KLF4 & Hs00358836_m1 & 110 & FAM \\
REX1 & Hs00358836_m1 & 102 & FAM \\
18S & 4352930E & 187 & FAM/MGB \\
\hline
\end{tabular}

conditions to show their multi-lineage differentiation potential (Figure 1A). In addition, it was verified that cells were negative $(\leq 19 \%)$ for CD45, CD34, and HLA-DR surface markers, and positive ( $\geq 97 \%)$ for CD90, CD73, and CD105, as well as CD9 and CD13 (the latter two specific for hEESCs and hESSCs, respectively) (Figure 1B).

\section{Cell-viability assay of SPIO-labeled MSCs}

Before performing MRI scans, viability of SPIO-labeled MSCs was determined by Trypan blue exclusion assay. Cell-viability values, compared the control group (100\%), with $99.23 \pm 3.18 \%$ in the BM-hMSC group, $101.53 \pm$ $5.6 \%$ in the hASC group, $96.4 \pm 1.75 \%$ in the hEESC group, $100.28 \pm 0.97 \%$ in the hESSC group, and $98.05 \pm$ $6.15 \%$ in the hAMC group, thus revealing that labeling with SPIO did not significantly affect cell viability and proliferation.

\section{In vivo tropism of MSCs to tumors, detected by non- invasive imaging techniques}

The ability of MSCs to migrate in vivo towards tumor sites was first determined through MRI (Figure 2). The study of expression of surface markers by flow cytometry did not bring about changes in MSCs phenotype after SPIO labeling (Figure 3A). The recruitment of SPIOlabeled MSCs to tumors resulted in a decrease in signal intensity (SI) and visualization of darker areas in tumor sites. Tumors were visible as lighter areas. The changes in SI were detected by T2-weighted images. Although no decrease in SI was detected in control animals (data not shown), changes in SI were seen in the different MSCs injected from the first determination at day 3. Images of hASCs, hEESCs, and hESSCs at day 3 showed a higher SI decrease than hAMCs and BM-hMSCs. These differences were more pronounced from day 10 , thus highlighting the differences in the ability of certain cells to migrate towards tumor areas. In all groups, SI decrease was observed first around the tumor sites and then inside the tumors, and was much more significant in hEESCs and hESSCs. To confirm these data, Prussian blue staining was used to detect SPIO-labeled MSCs in tumor sections obtained from animals scanned at day 24. Intense blue clusters were seen in tumor sections (Figure 3B). Higher-magnification images show the intra-cytoplasmic localization of the iron particles and the absence of extracellular iron. The number of Prussian blue-stained positive cells per HPF was calculated in tumor sections (Figure 3C). There were significantly more Prussian blue-stained positive cells in tumor sections of hESSCs $(66.1 \pm 3.72)$ compared with BMhMSCs $(23.6 \pm 3.30)$.

A second in vivo imaging technique, SPECT-CT, was performed. Selected tumor transverse sections of SPECTCT scans are shown in Figure 4A. The images obtained by 
Table 3 Primers used to amplify the migration-related genes

\begin{tabular}{|c|c|c|c|}
\hline Primer & GenBank accession number & Direction & Sequence $\left(5^{\prime} \rightarrow 3^{\prime}\right)$ \\
\hline \multirow[t]{2}{*}{ CXCR4 } & NM_003467 & Sense & TGGCCGACCTCCTCTITGT \\
\hline & & Anti-sense & AGTTTGCCACGGCATCAACT \\
\hline \multirow[t]{2}{*}{ SDF-1 (CXCL12) } & NM_000609 & Sense & CCAACGTCAAGCATCTCAAAATT \\
\hline & & Anti-sense & AGCCGGGCTCAATCTGAAG \\
\hline \multirow[t]{2}{*}{ RANTES (CCL5) } & NM_002985 & Sense & TGCCCACATCAAGGAGTATTTCTA \\
\hline & & Anti-sense & GCACACACTTGGCGGTTCT \\
\hline \multirow[t]{2}{*}{ MCP-1 (CCL2) } & NM_002990 & Sense & GCGTGGTGTTGCTAACCTTCA \\
\hline & & Anti-sense & GGCTCTTCATTGGCTCAGCTT \\
\hline \multirow[t]{2}{*}{ MMP-2 } & NM_004530 & Sense & TाTGATGACGATGAGCTATGGA \\
\hline & & Anti-sense & CCATCGGCGTTCCCATACT \\
\hline \multirow[t]{2}{*}{$18 \mathrm{~S}$} & NR_003286 & Sense & CGGCTACCACATCCAAGGAA \\
\hline & & Anti-sense & GCTGGAATTACCGCGGCT \\
\hline
\end{tabular}

SPECT-CT display a color spectrum, with the weakest signal being blue and the strongest red. In whole-body scans of control mice, an endogenous hNIS expression signal was present in the thyroid gland, salivary glands, stomach, and bladder. Accumulation of ${ }^{99 \mathrm{~m}} \mathrm{Tc}$, reflecting hNIS expression, was detected at tumor sites in animals that received the hNIS-labeled MSC injection. No signal was detected in tumor sites of the control animals (data not shown). Because MRI assays indicated differences in signal levels at first determinations, hiPSCs were included in the SPECT-CT assays to study whether pluripotency status can affect migration ability.

hMSCs did not exert any signal at day 3 , and their highest signal was found at day $10(1.92 \pm 0.72)$, after which it decreased until day $24(1.07 \pm 0.12)$. In hiPSCs and in the other hMSCs assayed, various levels of signal were detected from day 3, with hASCs presenting the lowest signal $(1.44 \pm 0.69)$ and hESSCs the highest $(2.01 \pm$ 0.18). Figure $4 \mathrm{~B}$ shows the differences at day 3 . The detected signals increased for the following determinations, with MSCs reaching their maximum level at day 17, when hESSCs also had their highest values (3.84 \pm 0.41$)$, whereas the highest signal for hiPSCs $(6.73 \pm 1.23)$ occurred at day 24. For MSCs, the detected signals decreased after 24 days, with the highest values being for hAMCs $(3.07 \pm 0.29)$ and hESSCs $(2.89 \pm 0.69)$, and the lowest for hASCs $(2.46 \pm 0.68)$ and hEESCs $(2.52 \pm$ $0.72)$. The tumor:muscle uptake ratio showed the differences between the migration ability of MSCs and hiPSCs (Figure 4C).

To confirm MSC and hiPSC engraftment, hNIS expression was performed by RT-PCR (Figure 5). At day 24 , the animals were euthanized, and RNA was extracted from tumors as described above. hNIS expression was detected in all groups with differences of intensity. These differences may be due to the differences seen in the distribution of MSCs and hiPSCs in tumors and also to episomal hNIS expression mediated by adenovirus. Findings suggest that MSCs and hiPSCs have the ability to migrate to and engraft into tumor sites. In SPIOlabeled MSCs and in hNIS-labeled MSCs and hiPSCs, the signal was maintained for up to 24 days after injection, depending on the cell type. BM-hMSCs showed the lowest migration ability, being detected in tumor sites at day 10, whereas hiPSCs showed the highest capacity, with increased signals until day 24. The other MSC types were detected from the first determination (day 3) and the signal was stronger until the final determination (day 24 ), thus revealing that more cells can reach tumor areas and remain there for longer periods.

\section{Pluripotency analysis}

To investigate whether pluripotency may be involved in the migration ability of MSCs, analysis of the expression of pluripotency-related genes was performed (Figure 6). qPCR analysis showed that the expression of the genes studied was significantly lower in MSCs compared with the control sample, hiPSCs (taken as 100\%). Moreover, differences were found in the expression levels between the MSCs. NANOG, and KLF4 expression was higher in hEESCs and hESSCs than in the other MSCs. There were no significant differences in SOX2 expression between the different MSCs, and OCT4 levels were very similar for MSCs as well, except for hAMCs in which expression was significantly lower (0.96\%). REX1 was expressed only in hESSCs and BM-hMSCs $(<0.01 \%)$. These results clearly show that although all cell types in the study may be considered MSCs, they exert a very different pluripotency pattern, and are also different from hiPSCs, which may be related to the differences in their engraftment capacity in addition to their effects on tumors. 


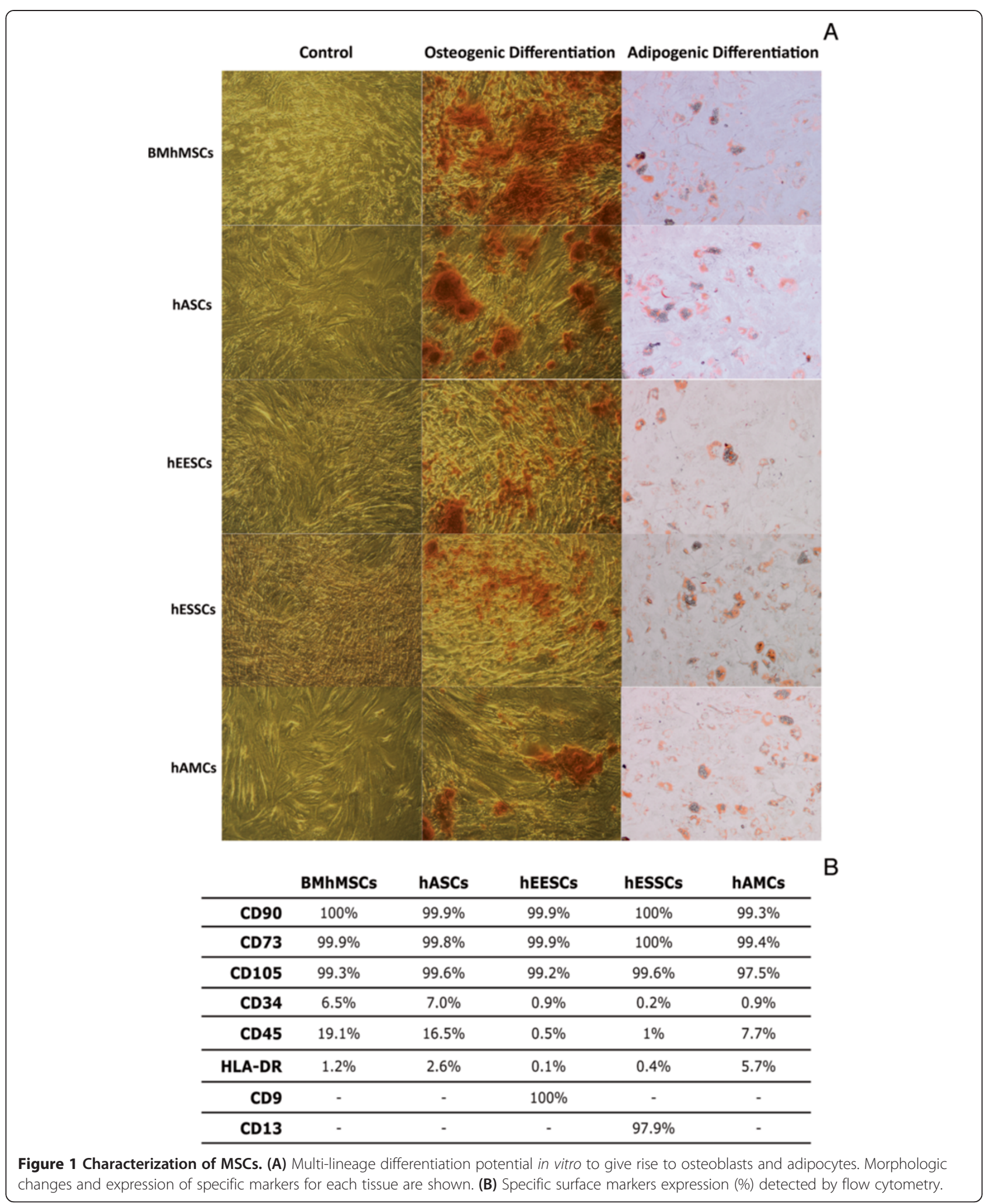

Effects on xenograft tumor growth

When tumors reached a size of $50 \mathrm{~mm}^{3}$, approximately 10 days after $\mathrm{HeLa}$ injection, the animals received intravenous injection of MSCs or hiPSCs (Figure 7). Tumor size was measured until the end of the experiments (34 days after HeLa injection and 24 days after 


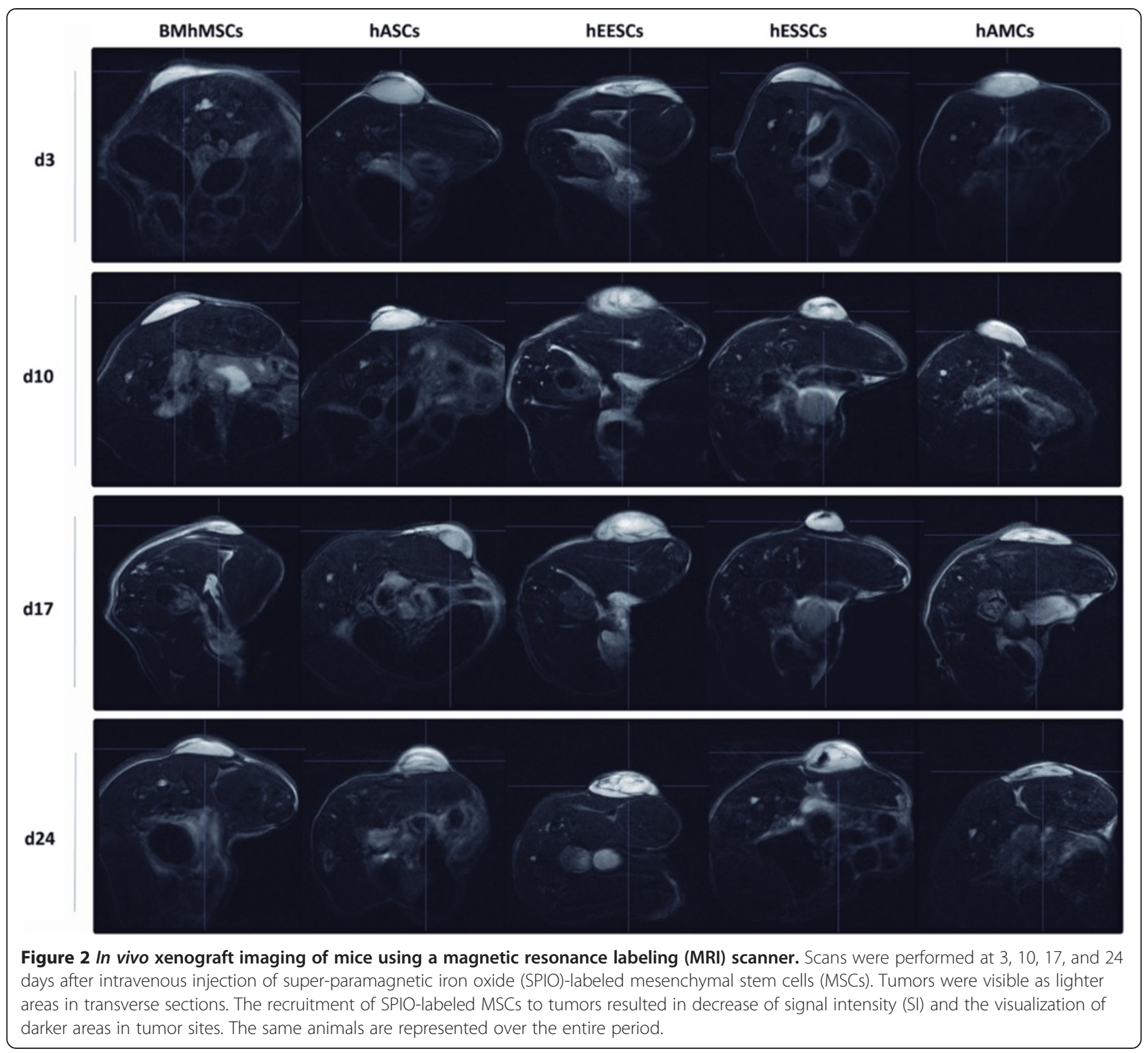

MSC or hiPSC injection). The growth of the tumors was clearly different depending on the type of MSCs or hiPSCs injected. Until day 13, the tumors of all the groups showed a similar growth pattern. However, differences between groups became clear at day 20, and were maintained until day 34 . At this point, control tumors consisting of HeLa cells had an average size of $110 \pm 26.8 \mathrm{~mm}^{3}$, whereas tumors composed of HeLa cells and MSCs had faster growth. Tumors resulting from the hEESC, hESSC, hASC, and hAMC injections reached a similar average size between 346 and 315 $\mathrm{mm}^{3}$, significantly larger than the control tumors except for those resulting from BM-hMSC injections (174.9 \pm $17.7 \mathrm{~mm}^{3}$ ). Tumors composed of HeLa cells and hiPSCs had the fastest growth rates and reached an average size of $594.8 \mathrm{~mm}^{3}$, significantly larger than those in the other groups. The significantly higher growth of HeLa cells and MSC or hiPSC tumors compared with the control group indicates migration and engraftment of these cells into tumors.

\section{Migration analysis}

To compare the expression of migration-related genes in tumors consisting only of HeLa cells (control group) and tumors consisting of HeLa cells and MSCs or hiPSCs, mRNAs encoding CXCR4, CXCL12, CCL5, CCL2, and MMP-2 were quantified by qPCR (Figure 8 ).

In general, expression levels of migration-related genes in tumors obtained from HeLa cells and MSC or hiPSC injection were significantly lower than those of control samples. CXCL12 expression was significantly decreased in all groups, with the smallest decrease seen in BMhMSCs $(-4.4 \pm 0.04$-times), and the largest in hASCs, 


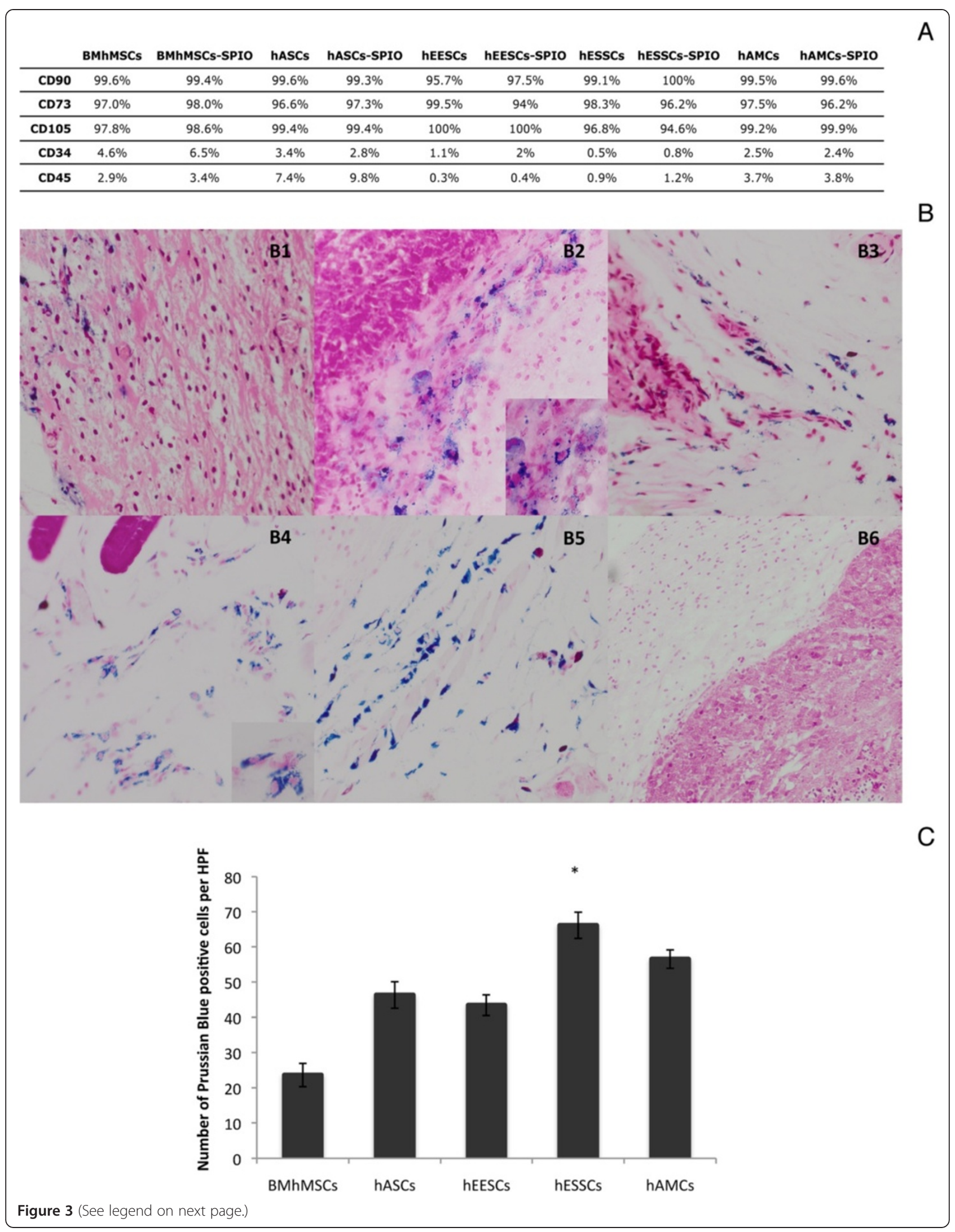


(See figure on previous page.)

Figure 3 Super-paramagnetic iron oxide (SPIO) labeling analysis. (A) Phenotypic analysis after SPIO labeling. Prussian blue staining in tumor sections obtained from animals scanned by MRI at day 24. (B) Images show intense blue clusters in tumor sections. (B1) SPIO-labeled bone marrow-derived human mesenchymal stem cells (BM-hMSCs); (B2) SPIO-labeled human adipose-derived stem cell (hASCs); (B3) SPIO-labeled human epithelial endometrium-derived stem cell (hEESCs); (B4) SPIO-labeled human stromal endometrium-derived stem cells (hESSCs); (B5) SPIOlabeled human amniotic membrane mesenchymal stem cells (hAMCs; (B6) control cells. Original magnification: (B1-B5) ×20; (B6) ×10. (C) number of Prussian blue-stained positive cells per high-power field (HPF) in tumor sections.

hEESCs, and hESSCs (between -9-fold and -11-fold). For CCL5, expression levels were significantly decreased in tumors obtained from BM-hMSCs $(-1.69 \pm 0.25-$ fold), hEESCs $(-2.31 \pm 0.08$-fold $)$, and hESSCs $(-2.58 \pm$ 0.08 -fold), but were significantly increased in hAMCs $(1.73 \pm 0.07$-fold $)$ and hiPSCs $(0.85 \pm 0.1$-fold $)$. In the hASC group, the expression level was similar to that of the control samples $(-0.25 \pm 0.12$-fold). CCL2 and CXCR4 expression levels were significantly decreased in tumors resulting from MSC injection, with the hAMC group showing the lowest decrease $(-1.05 \pm 0.07$-fold and $-0.98 \pm 0.12$-fold, respectively), whereas the hiPSC group had significantly increased expression levels (5.53 \pm 0.18 -fold and $0.60 \pm 0.33$-fold, respectively). Finally, MMP-2 expression was significantly decreased in tumors composed of HeLa cells and BM-hMSCs (-6.28 \pm 0.22-fold), hASCs $(-6.99 \pm 0.12$-fold), hEESCs $(-5.62 \pm$ 0.13 -fold), and hAMCs $(-3.09 \pm 0.06$-fold) but was significantly increased in hESSCs $(2.28 \pm 0.07$-fold $)$ and hiPSCs $(6.48 \pm 0.14$-fold). These findings highlight, once again, the differences between MSCs and hiPSCs. These differences may be responsible for the different migration patterns and probably play a role in the effects on the microenvironment in tumors.

\section{Discussion}

MSCs have been promoted as an attractive option for cellular delivery vehicles to carry anti-tumor agents, owing to their ability to home into tumor sites and secrete cytokines [28,33,34]. Previous studies have shown that systemic delivery of MSCs does not result in engraftment into healthy organs, but that they do migrate in various in vivo tumor models, although this mechanism has not yet been fully elucidated [35-42]. Additionally, MSCs can also counteract inflammation by suppressing host immune responses [28] and by secreting antiinflammatory cytokines [43].

The ability of MSCs and hiPSCs to migrate into tumor sites after systemic injection into mice is confirmed in the present study. HeLa-based subcutaneous xenograft tumors showed extensive MSC engraftment, and BMhMSC migration was significantly lower and slower than that obtained by the other MSCs and hiPSCs. All cell types were detected by MRI in a similar way to recent results obtained with MSCs by other groups [43]. Signals were obtained from the first (day 3) until the final (day 24) imaging determination, except in BM-hMSCs, which highlights the capacity of these cells to persist in tumor sites. These results and the differences between BMhMSCs and the other cell types were confirmed by ironparticle staining and the detection of hNIS in tumor samples. Using SPECT-CT images and hNIS expression, another study has shown BM-hMSC migration towards a breast-cancer model [44]. In contrast to our observations, hNIS expression in that study was detected in tumors from day 3 after MSC injection, which may be attributed to the differences between donors, tumor models, and the size of the pre-established tumor.

To clarify whether pluripotency plays a role in MSC migration to tumors, a pluripotency marker panel was analyzed. These studies revealed diminished expression of SOX2, NANOG, OCT4, KLF4, and REX1 compared with the control sample (hiPSCs). hEESCs and hESSCs, which displayed the highest signals in the imaging techniques, also had significant expression of KLF4, NANOG, and REX1 with respect to the other MSCs, although it was much lower than that shown by hiPSCs. These differences in pluripotency patterns may influence the differences in migration and engraftment of MSCs and hiPSCs.

Tumor growth confirmed the ability of MSCs to migrate into tumors, and the significant differences between BMhMSCs, the other MSCs, and hiPSCs. In a previous PC3 prostate xenograft model [45], intra-tumoral injection of hASCs also induced larger tumors compared with the control group, although the differences between control and hASC-induced tumors were smaller at the final time point $(<2$-fold vs. 3 -fold in ours). These differences may be attributed to the different tumor model used and the different procedures for hASC injection. However, there are also studies reporting inhibitory effects on tumor growth in an in vivo tumor model following MSC injection, using different approaches from ours [46,47]. The dose of MSCs delivered and the timing of injection have been highlighted as determining factors in the promotion or inhibition of tumor growth [28].

Although the mechanisms behind homing are not yet fully understood, the most likely cause of preferential migration is the release of chemotactic gradients from tumors. MSCs have a wide range of chemokine and cytokine receptors on their cell surface, which respond functionally to their ligands in vitro, whereas in vivo, 


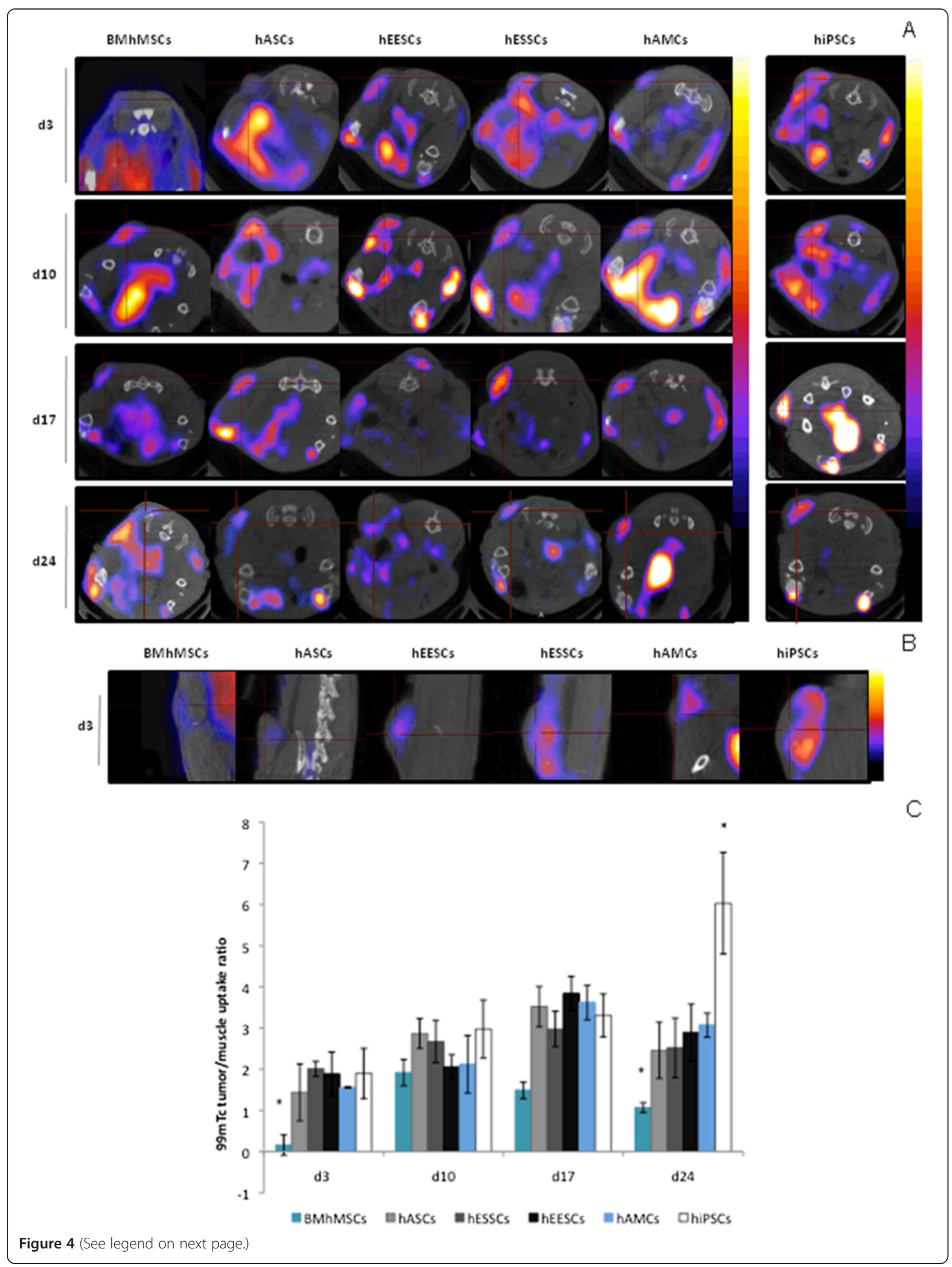


(See figure on previous page.)

Figure 4 In vivo xenograft imaging of mice using a nano-single-photon emission computed tomography/X-ray computed tomography (nano-SPECT-CT) scanner. Scans were performed at 3, 10, 17, and 24 days after intravenous injection of human sodium iodine symporter (hNIS)-labeled mesenchymal stem cells (MSCs) and human induced pluripotent stem cells (hiPSCs). An intravenous dose of 18.5 MBq of ${ }^{99 m}$ Tc was administered before the acquisitions. The same animals are represented over the entire period. hNIS expression is indicated by red crosses in transverse sections. Scans were performed after intravenous injection of hNIS-labeled MSCs or hiPSCs. (A) Images at days 3, 10, 17 and 24;

(B) images at day 3; (C): ${ }^{99 m}$ Tc tumor/muscle uptake ratio by hNIS-labeled MSCs or hiPSCs from days 3 to 24.

their modification implies changes in migration behavior [48-52].

Some authors have shwon that MSCs secrete a large panel of chemokines such as CXCL12, CCL2, and CCL5, which implies activation of the MAPK, FAK, and STAT signaling pathways, and the induction of biological responses $[48,49]$. Moreover, tumors produce a wide range of chemokines and cytokines, which may act as ligands for MSC receptors [35,53]. Of the different pairs of receptor/ligand described as responsible for migration, the CXCL12/CXCR4 pair should be highlighted. This has been studied in numerous works, both in vitro and in vivo, and using different tumor models or MSCs sources [35,49-51,54-59]. Loss of expression in MSC's receptors [48] implies a loss in cell-migration ability, indicating the great importance of these axes in MSC migration.

The relationship between homing and the inflammatory state has been assessed, and studies have been conducted in which BM-hMSCs were pre-treated with factors involved on inflammation (such as tumor necrosis factor, MMP2, CXCL12 and CCL5) [49]. But some studies were contradictory $[35,50]$, which it could be due to the variation in donors or cell-culture conditions (confluence, hypoxia, and passages) [60].

Our results show that, in general, when MSCs engraft into tumors, migration-related gene expression is decreased (whereas hiPSCs exert an increase) except for the CXCL12/CXCR4 axis, causing a significant depletion in the expression of both markers when MSCs are present. The exceptions were hiPSCs, in which CXCR4 expression increased. The reason for this may be that CXCL12 expression is also linked to more immature cell fractions, with higher expression in less committed stages of differentiation, that is, in cells closer to the embryonic state [61]. With regard to hiPSCs, this study and another previous work [62] are the first to highlight their in vivo migration ability to and long-term engraftment into tissue damage areas.

Besides the release of chemotactic gradients from the tumors, other explanations for MSCs migration could be the hypoxic conditions produced by tumor cells, which may cause MSCs to increase the expression of migratory signals [63], and thus confer the ability to cross the biological barriers [59]. However, in our study, a direct correlation between the migration patterns and the absence of oxygen does not seem to exist (data not shown).

Finally, a recent dialogue mediated by exosomes between MSCs from the bone marrow and tumoral cells in patients with melanoma [64] has been shown. The degree of exosome release by the various MSCs could determine the migratory differences between those cells, depending both on their area of origin and also on their exosome targeting.

\section{Conclusion}

This study clarifies the in vivo capacity of different types of MSCs and hiPSCs to migrate and engraft into a tumor model. The results reveal that the adult stem cells assayed were able to enter tumor sites and remain there, at least until the end of the experiments. Their different pluripotency pattern may also play a role in the

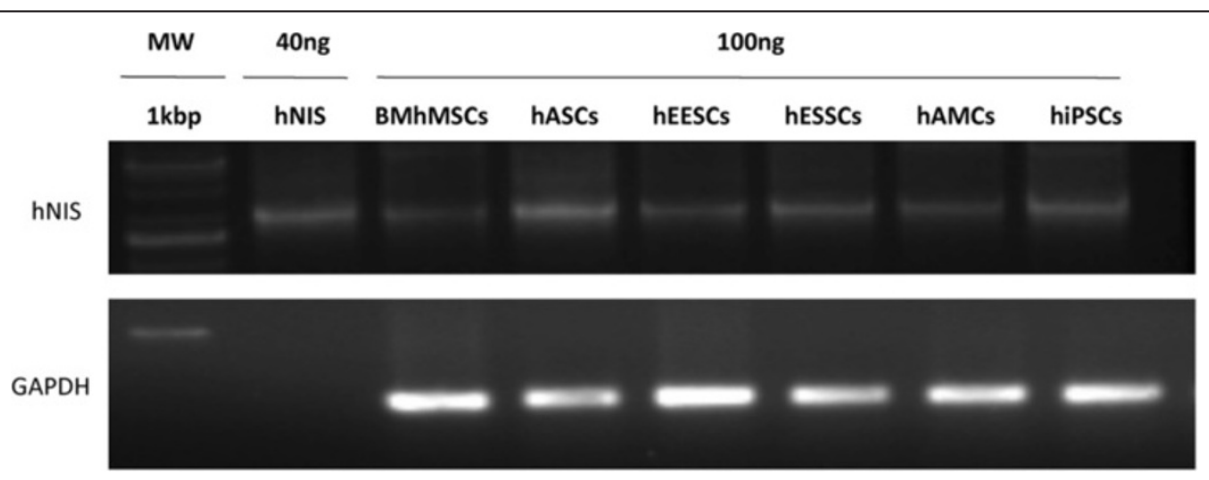

Figure 5 Detection of human sodium iodine symporter (hNIS) expression by reverse transcription (RT)-PCR. RNA was extracted from tumors of animals scanned by single-photon emission computed tomography/X-ray computed tomography (SPECT-CT) at day 24. 

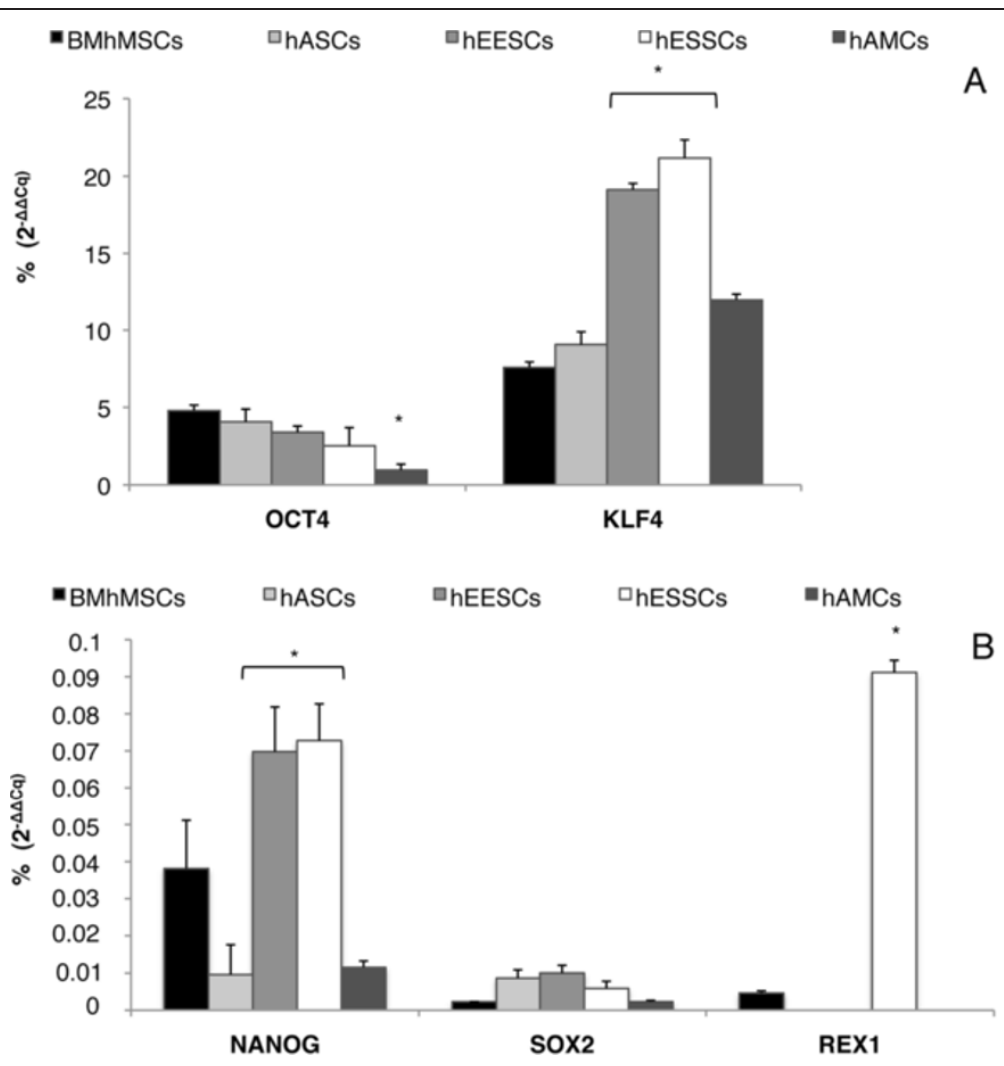

Figure 6 Pluripotency-related gene expression by quantitative (q)PCR. Gene expression levels were normalized against 18S rRNA. The ratio of the relative expression for each gene to $18 S$ was calculated by using the $2^{-\Delta \Delta \mathrm{Ca}}$ formula. hiPSC data were used as a calibrator for the results presented (100\%). (A) OCT4 and KLF4; (B) NANOG, SOX2 and REX1.
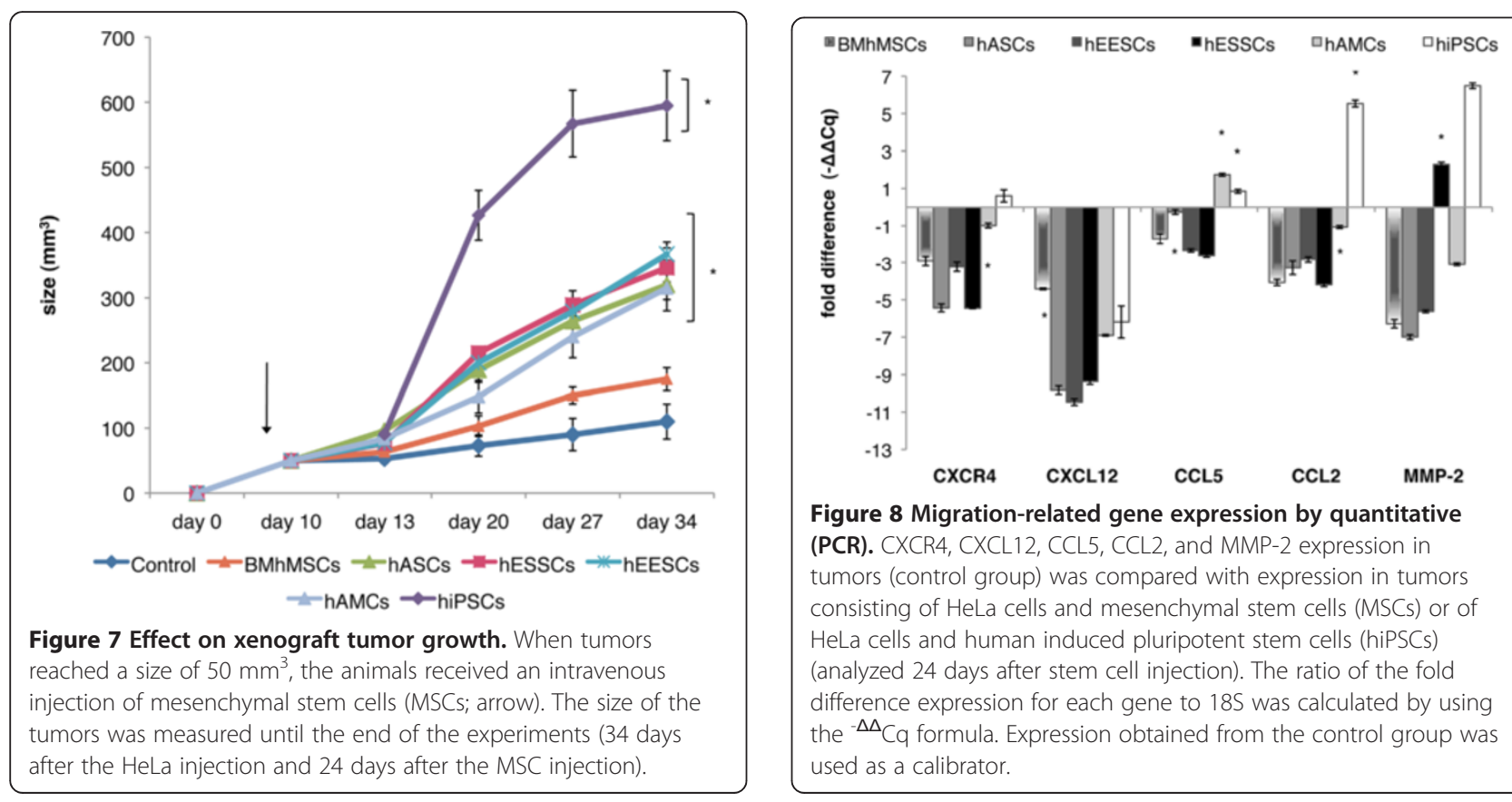

Figure 8 Migration-related gene expression by quantitative (PCR). CXCR4, CXCL12, CCL5, CCL2, and MMP-2 expression in tumors (control group) was compared with expression in tumors consisting of HeLa cells and mesenchymal stem cells (MSCs) or of HeLa cells and human induced pluripotent stem cells (hiPSCs) (analyzed 24 days after stem cell injection). The ratio of the fold difference expression for each gene to $18 \mathrm{~S}$ was calculated by using the ${ }^{-\Delta \Delta}$ Cq formula. Expression obtained from the control group was used as a calibrator. 
differences between these cell types, in which higher imaging signals but also higher tumor growth were obtained in those with highest expression of pluripotency genes. Moreover, MSCs and hiPSCs also exerted different migration-related gene profiles in tumors, which could be attributed to the anti-inflammatory effect exerted by MSCs, thereby diminishing expression of the migration marker. Our promising data support the importance of MSCs as therapeutic gene carriers in anti-tumor treatments, and highlight the importance of choosing the most suitable lineage for specific tumor lesion. Further understanding of the role of MSCs in tumors and the promising possibility to use them as therapeutic gene vehicles may lead to potentially fruitful treatment approaches.

\begin{abstract}
Abbreviations
AdhNIS: Ad10 Adenoviral vector containing human sodium iodine symporter gene; APC: Activated protein C; BM-hMSC: Bone marrow-derived human mesenchymal stem cell; CCL2: Chemokine (C-C motif) ligand 2;

CCL5: Chemokine (C-C motif) ligand 5; CXCL12: Chemokine (C-X-C motif) ligand 12; CXCR4: C-X-C chemokine receptor type 4; FACS: Fluorescenceactivated cell sorting; FBS: Fetal bovine serum; FITC: Fluorescein isothiocyanate; FOV: Field of view; GADPH: Glyceraldehyde-3-phosphate dehydrogenase; hAFMSC: Human amniotic fluid mesenchymal stem cell; hAMC: Human amniotic membrane mesenchymal stem cell; hASC: Human adipose-derived stem cell; hEESC: Human epithelial endometrium-derived stem cell; hESSC: Human stromal endometrium-derived stem cell; hiPSC: Human induced pluripotent stem cell; hNIS: Human sodium iodine symporter; HPF: High-power field; HSD: Honestly significant difference; ICEp: Endometrial epithelial stem cell lines; ICEs: Endometrial stromal stem cell lines; MCP-1: Monocyte chemotactic protein-1; MMP: Matrix metalloproteinase; MMP-2: Matrix metalloproteinase-2; MOI: Multiplicity of infection; MRI: Magnetic resonance imaging; MSC: Mesenchymal stem cell; PE: Phycoerythrin; PerCP: Peridinin chlorophyll protein complex; pFU: Plaqueforming unit; QPCR: Quantitative polymerase chain reaction; PBS: Phosphatebuffered saline; RANTES: (Regulated on Activation, Normal T cell Expressed and Secreted); RARE: Rapid acquisition with relaxation enhancement; RT: Reverse transcription; SC: Subcutaneous; SDF-1: Stromal cell-derived factor-1; SI: Signal intensity; SPECT-CT: Single-photon emission computed tomography/X-ray computed tomography; SPIO: Super-paramagnetic iron oxide; TE: Echo time; TR: Repetition time; VOI: Volumes of interest.
\end{abstract}

\section{Competing interests}

The authors indicate no competing financial interests.

\section{Authors' contributions}

CB-L participated in the design of the study, performed most of the experimental procedures, collected data, made the calculations, and participated in statistical analysis and in manuscript writing. GM participated in data analysis and interpretations, statistical analysis, and manuscript writing. DO and JB participated in the SPECT experiments. CS and IC carried out the collection and characterization of hEESCs and hESSCs. MI and JCR participated in the in vitro studies. PL-L performed MRI imaging acquisition. MQ participated in the in vivo studies. PM-D was the responsible of the conception and design of the study and participated in the in vivo studies, coordinated the study, and reviewed and corrected the manuscript. All authors read and approved the manuscript.

\section{Authors' information}

CB-L is a pre-doctoral staff member at the Instituto Aragones de Ciencias de la Salud-IIS Aragón, Zaragoza, Spain. GM is a post-doctoral fellow at the Instituto Aragones de Ciencias de la Salud-IIS Aragón, Zaragoza, Spain. DO is a visiting teacher at the Department of Medical Biochemistry and Microbiology, Uppsala University, Sweden. JB is a laboratory technician at the Queen Mary University of London, UK. CS is Full Professor of Obstetrics and Gynecology at the University of Valencia (Spain) and Scientific Head of the IVI. IC is Principal Investigator at IVI Foundation, Valencia, Spain. MI is
Professor of Biochemistry and Dean of Faculty of Health Sciences at the University Francisco de Vitoria, Spain. JCR is Head of the Viral Vectors Unit at the Centro Nacional de Investigaciones Cardiovasculares, Spain. PL-L and MQ are Principal Investigators at the Instituto de Investigaciones Biomédicas Alberto Sols, Spain. PM-D is ARAID Foundation Principal Investigator, professor at University Francisco de Vitoria, Spain, and Head of the Gene and Therapy Group at the Instituto Aragones de Ciencias de la Salud-IIS Aragon, Zaragoza, Spain.

\section{Acknowledgments}

This work was supported by FIS (PI080750), DGA (PI041/08, B84, PI086/09), MMA Fund (ICS/08/0050), PROMETEO/2008/163; CTQ-2010-20960-C02-02; S2010/BMD-2349, PIPAMER-0912, and PIPAMER-1214. CB-L was funded by fellowships ICS/08/0050 and DGA PI-086/09, GM by PIPAMER-0912, and PMD by the Araid Fund. We are grateful to Dr Hugo Cabedo and Dr Jose Antonio Gómez-Sánchez for help with the qPCR studies, and to Juan Miguel Sanchez, Camino Latorre, and Rebeca Guerrero for technical assistance. We also thank Professor James McCue and Dr Nancy d'Cruz for their assistance in language editing.

\section{Author details}

${ }^{1}$ Instituto Aragones de Ciencias de la Salud-IIS Aragon, Zaragoza, Spain. ${ }^{2}$ Department of Medical Biochemistry and Microbiology, The Biomedical Centre, Uppsala University, Uppsala, Sweden. ${ }^{3}$ Queen Mary, University of London/Cancer Research UK, London, UK. ${ }^{4}$ Fundacion IVI, Instituto Universitario IVI, University of Valencia, Institute of Health Research INCLIVA, Valencia, Spain. ${ }^{5}$ Facultad de Ciencias Biosanitarias, Universidad Francisco de Vitoria, Madrid, Spain. ${ }^{6}$ Centro Nacional de Investigaciones Cardiovasculares, Madrid, Spain. ${ }^{7}$ Instituto de Investigaciones Biomedicas Alberto Sols (CSIC-UAM), Madrid, Spain. ${ }^{8}$ Fundacion Araid, Zaragoza, Spain.

Received: 24 July 2012 Accepted: 19 April 2013

Published: 28 May 2013

\section{References}

1. Kansas GS: Selectins and their ligands: current concepts and controversies. Blood 1996, 88:3259-3287.

2. Rüster B, Göttig $S$, Ludwig RJ, Bistrian R, Müller $S$, Seifried E, Gille J, Henschler R: Mesenchymal stem cells display coordinated rolling and adhesion behavior on endothelial cells. Blood 2006, 108:3938-3944.

3. Schweitzer KM, Dräger AM, van der Valk P, Thijsen SF, Zevenbergen A, Theijsmeijer AP, van der Schoot CE, Langenhuijsen MM: Constitutive expression of E-selectin and vascular cell adhesion molecule-1 on endothelial cells of hematopoietic tissues. Am J Pathol 1996, 148:165-175.

4. De Miguel MP, Fuentes-Julian S, Blazquez-Martinez A, Pascual CY, Aller MA, Arias J, Arnalich-Montiel F: Immunosuppressive properties of mesenchymal stem cells: advances and applications. Curr Mol Med 2012, 12:574-591.

5. Salem HK, Thiemermann C: Mesenchymal stromal cells: current understanding and clinical status. Stem Cells 2010, 28:585-596.

6. Kidd S, Caldwell L, Dietrich M, Samudio I, Spaeth EL, Watson K, Shi Y, Abbruzzese J, Konopleva M, Andreeff M, Marini FC: Mesenchymal stromal cells alone or expressing interferon-beta suppress pancreatic tumors in vivo, an effect countered by anti-inflammatory treatment. Cytotherapy 2010, 12:615-625.

7. Studeny M, Marini FC, Champlin RE, Zompetta C, Fidler IJ, Andreeff M: Bone marrow-derived mesenchymal stem cells as vehicles for interferon-beta delivery into tumors. Cancer Res 2002, 62:3603-3608.

8. Yong RL, Shinojima N, Fueyo J, Gumin J, Vecil GG, Marini FC, Bogler O, Andreeff M, Lang FF: Human bone marrow-derived mesenchymal stem cells for intravascular delivery of oncolytic adenovirus Delta24-RGD to human gliomas. Cancer Res 2009, 69:8932-8940.

9. Friedenstein AJ, Petrakova KV, Kurolesova Al, Frolova GP: Heterotopic of bone marrow. Analysis of precursor cells for osteogenic and hematopoietic tissues. Transplantation 1968, 6:230-247.

10. Friedenstein AJ, Piatetzky-Shapiro II, Petrakova KV: Osteogenesis in transplants of bone marrow cells. J Embryol Exp Morphol 1966, 16:381-390.

11. Baksh D, Song L, Tuan RS: Adult mesenchymal stem cells: characterization, differentiation, and application in cell and gene therapy. J Cell Mol Med 2004, 8:301-316. 
12. Cervelló I, Gil-Sanchis C, Mas A, Delgado-Rosas F, Martínez-Conejero JA, Galán A, Martínez-Romero A, Martínez S, Navarro I, Ferro J, Horcajadas JA, Esteban FJ, O'Connor JE, Pellicer A, Simón C: Human endometrial side population cells exhibit genotypic, phenotypic and functional features of somatic stem cells. PLoS One 2010, 5:e10964.

13. Cervelló I, Mas A, Gil-Sanchis C, Peris L, Faus A, Saunders PT, Critchley HO, Simón C: Reconstruction of endometrium from human endometrial side population cell lines. PLoS One 2011, 6:e21221.

14. Chiu RC: Bone-marrow stem cells as a source for cell therapy. Heart Fail Rev 2003, 8:247-251.

15. Dubois SG, Floyd EZ, Zvonic S, Kilroy G, Wu X, Carling S, Halvorsen YD, Ravussin E, Gimble JM: Isolation of human adipose-derived stem cells from biopsies and liposuction specimens. Methods Mol Biol 2008, 449:69-79.

16. Gargett CE, Schwab KE, Zillwood RM, Nguyen HP, Wu D: Isolation and culture of epithelial progenitors and mesenchymal stem cells from human endometrium. Biol Reprod 2009, 80:1136-1145.

17. Shih YR, Kuo TK, Yang AH, Lee OK, Lee CH: Isolation and characterization of stem cells from the human parathyroid gland. Cell Prolif 2009, 42:461-470.

18. Zuk PA, Zhu M, Mizuno H, Huang J, Futrell JW, Katz AJ, Benhaim P, Lorenz $H P$, Hedrick MH: Multilineage cells from human adipose tissue: implications for cell-based therapies. Tissue Eng 2001, 7:211-228.

19. Zvaifler NJ, Marinova-Mutafchieva L, Adams G, Edwards CJ, Moss J, Burger JA, Maini RN: Mesenchymal precursor cells in the blood of normal individuals. Arthritis Res 2000, 2:477-488.

20. Bieback K, Klüter $\mathrm{H}$ : Mesenchymal stromal cells from umbilical cord blood. Curr Stem Cell Res Ther 2007, 2:310-323.

21. Campagnoli C, Roberts IA, Kumar S, Bennett PR, Bellantuono I, Fisk NM: Identification of mesenchymal stem/progenitor cells in human firsttrimester fetal blood, liver, and bone marrow. Blood 2001, 98:2396-2402.

22. Gang EJ, Hong SH, Jeong JA, Hwang SH, Kim SW, Yang IH, Ahn C, Han H, $\mathrm{Kim} \mathrm{H}$ : In vitro mesengenic potential of human umbilical cord bloodderived mesenchymal stem cells. Biochem Biophys Res Commun 2004, 321:102-108.

23. In't Anker PS, Noort WA, Scherjon SA, Kleijburg-van der Keur C, Kruisselbrink $A B$, van Bezooijen RL, Beekhuizen W, Willemze R, Kanhai HH, Fibbe WE: Mesenchymal stem cells in human second-trimester bone marrow, liver, lung, and spleen exhibit a similar immunophenotype but a heterogeneous multilineage differentiation potential. Haematologica 2003, 88:845-852.

24. Anker PS I't, Scherjon SA, Kleijburg-van der Keur C, de Groot-Swings GM, Claas FH, Fibbe WE, Kanhai HH: Isolation of mesenchymal stem cells of fetal or maternal origin from human placenta. Stem Cells 2004, 22:1338-1345

25. Zhang $X$, Hirai M, Cantero S, Ciubotariu R, Dobrila L, Hirsh A, Igura K, Satoh H, Yokomi I, Nishimura T, Yamaguchi S, Yoshimura K, Rubinstein P, Takahashi TA: Isolation and characterization of mesenchymal stem cells from human umbilical cord blood: reevaluation of critical factors for successful isolation and high ability to proliferate and differentiate to chondrocytes as compared to mesenchymal stem cells from bone marrow and adipose tissue. J Cell Biochem 2011, 112:1206-1218.

26. Pittenger MF, Mackay AM, Beck SC, Jaiswal RK, Douglas R, Mosca JD, Moorman MA, Simonetti DW, Craig S, Marshak DR: Multilineage potential of adult human mesenchymal stem cells. Science 1999, 284:143-147.

27. Dominici M, Le Blanc K, Mueller I, Slaper-Cortenbach I, Marini F, Krause D, Deans R, Keating A, Prockop D, Horwitz E: Minimal criteria for defining multipotent mesenchymal stromal cells. The International Society for Cellular Therapy position statement. Cytotherapy 2006, 8:315-317.

28. Klopp AH, Gupta A, Spaeth E, Andreeff M, Marini F 3rd: Concise review: Dissecting a discrepancy in the literature: do mesenchymal stem cells support or suppress tumor growth? Stem Cells 2011, 29:11-19.

29. Groot-Wassink T, Aboagye EO, Glaser M, Lemoine NR, Vassaux G Adenovirus biodistribution and noninvasive imaging of gene expression in vivo by positron emission tomography using human sodium/iodide symporter as reporter gene. Hum Gene Ther 2002, 13:1723-1735.

30. Martin-Duque $P$, Jezzard S, Kaftansis L, Vassaux G: Direct comparison of the insulating properties of two genetic elements in an adenoviral vector containing two different expression cassettes. Hum Gene Ther 2004, 15:995-1002.

31. Martín-Duque P, Quintanilla M, McNeish I, Lopes R, Romero J, Romero D, Lemoine NR, Ramón y Cajal S, Vassaux G: Caspase-1 as a radio- and chemo-sensitiser in vitro and in vivo. Int J Mol Med 2006, 17:841-847.
32. Henning TD, Boddington S, Daldrup-Link HE: Labeling hESCs and MSCs with iron oxide nanoparticles for non-invasive in vivo tracking with MR imaging. J Vis Exp 2008, 13:685

33. Loebinger MR, Janes SM: Stem cells as vectors for antitumor therapy. Thorax 2010, 65:362-369.

34. Pereboeva L, Komarova S, Mikheeva G, Krasnykh V, Curiel DT: Approaches to utilize mesenchymal progenitor cells as cellular vehicles. Stem Cells 2003, 21:389-404.

35. Dwyer RM, Potter-Beirne SM, Harrington KA, Lowery AJ, Hennessy E, Murphy JM, Barry FP, O'Brien T, Kerin MJ: Monocyte chemotactic protein-1 secreted by primary breast tumors stimulates migration of mesenchymal stem cells. Clin Cancer Res 2007, 13:5020-5027.

36. Khakoo AY, Pati S, Anderson SA, Reid W, Elshal MF, Rovira II, Nguyen AT, Malide D, Combs CA, Hall G, Zhang J, Raffeld M, Rogers TB, StetlerStevenson W, Frank JA, Reitz M, Finkel T: Human mesenchymal stem cells exert potent antitumorigenic effects in a model of Kaposi's sarcoma. J Exp Med 2006, 203:1235-1247.

37. Komarova S, Kawakami Y, Stoff-Khalili MA, Curiel DT, Pereboeva L: Mesenchymal progenitor cells as cellular vehicles for delivery of oncolytic adenoviruses. Mol Cancer Ther 2006, 5:755-766.

38. Loebinger MR, Eddaoudi A, Davies D, Janes SM: Mesenchymal stem cell delivery of TRAIL can eliminate metastatic cancer. Cancer Res 2009, 69:4134-4142.

39. Pereboeva L, Curiel DT: Cellular vehicles for cancer gene therapy: current status and future potential. Bio-Drugs 2004, 18:361-385.

40. Shinagawa K, Kitadai Y, Tanaka M, Sumida T, Kodama M, Higashi Y, Tanaka S, Yasui W, Chayama K: Mesenchymal stem cells enhance growth and metastasis of colon cancer. Int J Cancer 2010, 127:2323-2333.

41. Stoff-Khalili MA, Rivera AA, Mathis JM, Banerjee NS, Moon AS, Hess A, Rocconi RP, Numnum TM, Everts M, Chow LT, Douglas JT, Siegal GP, Zhu ZB, Bender HG, Dall P, Stoff A, Pereboeva L, Curiel DT: Mesenchymal stem cells as a vehicle for targeted delivery of CRAds to lung metastases of breast carcinoma. Breast Cancer Res Treat 2007, 105:157-167.

42. Studeny M, Marini FC, Dembinski JL, Zompetta C, Cabreira-Hansen M, Bekele BN, Champlin RE, Andreeff M: Mesenchymal stem cells: potential precursors for tumor stroma and targeted-delivery vehicles for anticancer agents. J Nat/ Cancer Inst 2004, 96:1593-1603.

43. Eiró N, Vizoso FJ: Inflammation and cancer. World J Gastrointest Surg 2012, 4:62-72.

44. Dwyer RM, Ryan J, Havelin RJ, Morris JC, Miller BW, Liu Z, Flavin R, O'Flatharta C, Foley MJ, Barrett HH, Murphy JM, Barry FP, O'Brien T, Kerin MJ: Mesenchymal stem cell-mediated delivery of the sodium iodide symporter supports radionuclide imaging and treatment of breast cancer. Stem Cells 2011, 29:1149-1157.

45. Lin G, Yang R, Banie L, Wang G, Ning H, Li LC, Lue TF, Lin CS: Effects of transplantation of adipose tissue-derived stem cells on prostate tumor. Prostate 2010, 70:1066-1073.

46. Cousin B, Ravet E, Poglio S, De Toni F, Bertuzzi M, Lulka H, Touil I, André M, Grolleau JL, Péron JM, Chavoin JP, Bourin P, Pénicaud L, Casteilla L, Buscail L, Cordelier P: Adult stromal cells derived from human adipose tissue provoke pancreatic cancer cell death both in vitro and in vivo. PLOS One 2009, 4:e6278.

47. Secchiero P, Zorzet S, Tripodo C, Corallini F, Melloni E, Caruso L, Bosco R, Ingrao S, Zavan B, Zauli G: Human bone marrow mesenchymal stem cells display anti-cancer activity in SCID mice bearing disseminated nonHodgkin's lymphoma xenografts. PLoS One 2010, 5:e11140.

48. Honczarenko M, Le Y, Swierkowski M, Ghiran I, Glodek AM, Silberstein LE: Human bone marrow stromal cells express a distinct set of biologically functional chemokine receptors. Stem Cells 2006, 24:1030-1041.

49. Ponte AL, Marais E, Gallay N, Langonné A, Delorme B, Hérault O, Charbord $\mathrm{P}$, Domenech J: The in vitro migration capacity of human bone marrow mesenchymal stem cells: comparison of chemokine and growth factor chemotactic activities. Stem Cells 2007, 25:1737-1745.

50. Ringe J, Strassburg S, Neumann K, Endres M, Notter M, Burmester GR, Kaps C, Sittinger M: Towards in situ tissue repair: human mesenchymal stem cells express chemokine receptors CXCR1, CXCR2 and CCR2, and migrate upon stimulation with CXCL8 but not CCL2. J Cell Biochem 2007, 101:135-146.

51. Sordi V, Malosio ML, Marchesi F, Mercalli A, Melzi R, Giordano T, Belmonte N, Ferrari G, Leone BE, Bertuzzi F, Zerbini G, Allavena P, Bonifacio E, Piemonti L: Bone marrow mesenchymal stem cells express a restricted set of functionally active chemokine receptors capable of promoting migration to pancreatic islets. Blood 2005, 106:419-427. 
52. Von Lüttichau I, Notohamiprodjo M, Wechselberger A, Peters C, Henger A, Seliger C, Djafarzadeh R, Huss R, Nelson PJ: Human adult CD34- progenitor cells functionally express the chemokine receptors CCR1, CCR4, CCR7, CXCR5, and CCR10 but not CXCR4. Stem Cells Dev 2005, 14:329-336.

53. Dai LJ, Moniri MR, Zeng ZR, Zhou JX, Rayat J, Warnock GL: Potential implications of mesenchymal stem cells in cancer therapy. Cancer Lett 2011, 305:8-20.

54. Orimo A, Gupta PB, Sgroi DC, Arenzana-Seisdedos F, Delaunay T, Naeem R, Carey VJ, Richardson AL, Weinberg RA: Stromal fibroblasts present in invasive human breast carcinomas promote tumor growth and angiogenesis through elevated SDF-1/CXCL12 secretion. Cell 2005 121:335-348.

55. Heissig B, Hattori K, Dias S, Friedrich M, Ferris B, Hackett NR, Crystal RG, Besmer P, Lyden D, Moore MA, Werb Z, Rafii S: Recruitment of stem and progenitor cells from the bone marrow niche requires MMP-9 mediated release of kit-ligand. Cell 2002, 109:625-637.

56. Petit I, Szyper-Kravitz M, Nagler A, Lahav M, Peled A, Habler L, Ponomaryov T, Taichman RS, Arenzana-Seisdedos F, Fujii N, Sandbank J, Zipori D, Lapidot T: G-CSF induces stem cell mobilization by decreasing bone marrow SDF-1 and up-regulating CXCR4. Nat Immunol 2002, 3:687-694.

57. Kang NH, Hwang KA, Kim SU, Kim YB, Hyun SH, Jeung EB, Choi KC: Human amniotic fluid-derived stem cells expressing cytosine deaminase and thymidine kinase inhibits the growth of breast cancer cells in cellular and xenograft mouse models. Cancer Gene Ther 2012, 19:412-419.

58. Yang DY, Sheu ML, Su HL, Cheng FC, Chen YJ, Chen CJ, Chiu WT, Yiin JJ, Sheehan J, Pan HC: Dual regeneration of muscle and nerve by intravenous administration of human amniotic fluid-derived mesenchymal stem cells regulated by stromal cell-derived factor-1a in a sciatic nerve injury model. J Neurosurg 2012, 116:1357-1367.

59. Bhoopathi P, Chetty C, Gogineni VR, Gujrati M, Dinh DH, Rao JS, Lakka SS: MMP-2 mediates mesenchymal stem cell tropism towards medulloblastoma tumors. Gene Ther 2011, 18:692-701.

60. Dawson MR, Chae SS, Jain RK, Duda DG: Direct evidence for lineagedependent effects of bone marrow stromal cells on tumor progression. Am J Cancer Res 2011, 1:144-154.

61. Kortesidis A, Zannettino A, Isenmann S, Shi S, Lapidot T, Gronthos S: Stromal-derived factor-1 promotes the growth, survival, and development of human bone marrow stromal stem cells. Blood 2005, 105:3793-3801.

62. Templin C, Zweigerdt R, Schwanke K, Olmer R, Ghadri JR, Emmert MY, Müller E, Küest SM, Cohrs S, Schibli R, Kronen P, Hilbe M, Reinisch A, Strunk D, Haverich A, Hoerstrup S, Lüscher TF, Kaufmann PA, Landmesser U, Martin $\mathrm{U}$ : Transplantation and tracking of human induced pluripotent stem cells in a pig model of myocardial infarction: assessment of cell survival, engraftment and distribution by hybrid SPECT-CT imaging of sodium iodide symporter trangene expression. Circulation. in press.

63. Vertelov G, Kharazi L, Muralidhar MG, Sanati G, Tankovich T, Kharazi A: High targeted migration of human mesenchymal stem cells grown in hypoxia is associated with enhanced activation of RhoA. Stem Cell Res Ther 2013, 4:5.

64. Peinado H, Alečković M, Lavotshkin S, Matei I, Costa-Silva B, Moreno-Bueno G, Hergueta-Redondo M, Williams C, García-Santos G, Ghajar C, NitadoriHoshino A, Hoffman C, Badal K, Garcia BA, Callahan MK, Yuan J, Martins VR, Skog J, Kaplan RN, Brady MS, Wolchok JD, Chapman PB, Kang Y, Bromberg J, Lyden D: Melanoma exosomes educate bone marrow progenitor cells toward a pro-metastatic phenotype through MET. Nat Med 2012, 18:883-891.

doi:10.1186/1741-7015-11-139

Cite this article as: Belmar-Lopez et al:: Tissue-derived mesenchymal stromal cells used as vehicles for anti-tumor therapy exert different in vivo effects on migration capacity and tumor growth. BMC Medicine 2013 11:139.

\section{Submit your next manuscript to BioMed Central and take full advantage of:}

- Convenient online submission

- Thorough peer review

- No space constraints or color figure charges

- Immediate publication on acceptance

- Inclusion in PubMed, CAS, Scopus and Google Scholar

- Research which is freely available for redistribution

Submit your manuscript at www.biomedcentral.com/submit
( BioMed Central 